\title{
BUILDING A SYSTEM FOR LOGISTICS INFORMATION SYSTEMS EVALUATION
}

\author{
Murad OMAROV ${ }^{1}$, Artem SUKHOMLYNOV ${ }^{1, *}$ \\ ${ }^{1}$ Kharkiv National University of Radio Electronics, Kharkiv, Ukraine
}

\begin{abstract}
The article analyzes the criteria by which to evaluate the logistics systems and shows the process of forming a system of logistics information systems evaluation, based on the criteria used by qualitative scales. The article also analyzes modern technologies of information systems development, in particular the technology of object-relational mapping. There has been considered the application of the built evaluation system in the research logistics information system.
\end{abstract}

Keywords: Logistics system; Evaluation criterion; Material flow; Multiset model of material flow

\section{INTRODUCTION}

Modern enterprise management information systems (EMISs) are constantly being improved and modernized. They have passed a difficult way of development from "material needs planning" $[1,2]$, to "enterprise resource planning" [3] and "resource management and external relations of the enterprise" [4]. Almost all modern EMISs include information management systems for internal (production) logistics. Also, EMISs can include support of external logistics (procurement and distribution). These logistics information systems (LISs) can be both separate software products and one of the components of integrated EMISs.

The widespread use of mobile devices in EMISs has become the trend of the recent years. The development of mobile devices and $\mathrm{WiFi}$ access to the Internet opens up new opportunities in the enterprise management in general and in logistics in particular. The development and availability of Global Positioning System (GPS) satellite systems has a particularly significant impact on logistics systems.

In order to maintain competitiveness under the conditions of modern global economy, which is constantly evolving and becoming more sophisticated, almost every enterprise is forced to perform the restructuring of its relations with the environment [5], and this requires the ability of EMISs to meet the new requirements of the management component of the enterprise.

The author has developed a multiset material flow model [6] based on the theory of multisets [7]. This model includes a set of operations on material flow. In [8], the author proved that the operations of a multiset material flow model have an algorithmic implementation. Also, the author has analyzed [9] the typical ISMS architecture and the place of decision support components in the ISMSs, and has studied the methods of making managerial decisions in logistics. In addition, the author has determined in [8] the requirements for the data model, which has been proposed in [6], of the accompanying information flow for the material flow.

From this perspective, the author [9] has proposed to create ISMS production logistics subsystems based on the material flow model and to include decision support components into them. It has

*Corresponding Author: artem.sukhomlinov@nure.ua

Received: 12.10.2019 Published: 16.12.2019 
allowed to project, develop and implement the system of internal production logistics of the real enterprise LIS on the basis of multichannel model of material flows.

The IT industry has accumulated a vast experience of designing, developing and implementing software, in particular, information systems. This experience has been analyzed and generalized by the world science and has been concentrated in the educational discipline "Software Development" which has been included into the educational programs for IT specialists in various fields.

The objective of this study is to build a multi-criteria evaluation system for a LIS and to apply it to a research LIS.

\section{ANALYSIS OF MODERN AVAILABLE TECHNICAL MEANS THAT MAY BE USED FOR AUTOMATION OF LOGISTICS SYSTEMS}

When designing an automated management system for production logistics, it is necessary to determine which part of the logistics system is to be automated and which part remains in the manual mode. This ratio is determined not only by the wishes of the owner of the problem, but also by the capability of the software implementation of certain functional tasks of the logistics system. At the moment, despite the significant achievements in the field of artificial intelligence, the human factor continues to be present in the logistics system. Therefore, the automated system of production logistics management will include modules which operate in an automate mode, for example, collecting and inputting data from various sensors, as well as modules which allow only to automate some functions of the logistics system, such as procurement planning or staff motivation.

Let's consider modern technical capabilities of logistics system automation, which are commonly available.

First of all, these are object localization technologies, such as GPS. Secondly, these are one- and twodimensional bar codes, the use of which has become widespread because of their cheapness, reliability and ease of implementation. In addition, image recognition systems have become commonly available; in particular, the identification of car license plates, carriage numbers, etc. And it is worth to mention the rapid introduction of mobile devices - tablets and smartphones, which together with WiFi and Blue Tooth data transfer technologies allow to create software with new functionality.

\section{SYSTEM OF LIS EVALUATION}

An evaluation system is created for decision-making in difficult situations, when there is no way to rely on the obviousness of the best solution out of several possible. The system allows you to compare different solutions (alternatives) and choose the best option within specific conditions.

To create a rating system, a set of criteria should be selected, with its own rating scale and rules for comparing alternatives. The rating scale by criterion should be sequenced by a set of values. In the theory of decision making, these scales are usually brought from the best rating to the worst. That is, for the rating scale

$$
\Xi=\left\langle\xi_{1}, \ldots, \xi_{n}\right\rangle
$$

which is an ordered set for any $i \in[1, n]$ the ratio is executed $\xi_{i}>\xi_{i+1}$, where $>$ - is a "be better" comparison operation. There are several methods for developing rules for comparing alternatives [10, $11]$. 
It is obvious that the LIS management evaluation system should contain both the criteria related to the improvement of the enterprise logistics system management process and the criteria for the evaluation of the LIS as a software product, i.e. from the point of view of information management.

The criteria of perfection of the enterprise logistics system management process depend on the criteria of evaluation of the logistics system efficiency. Currently, there is no unanimous opinion on the assessment of the logistics system efficiency, i.e. this issue is still a subject of research in logistics. But the majority of researchers distinguish the following criteria:

- expenses;

- user satisfaction;

- time indicators;

- assets (efficiency of capital use).

Let's briefly consider these criteria and form simple scales of "qualitative" estimations by them. The "Expenses" criterion characterizes the cost of logistics expenses in the total amount of production costs. Usually this criterion is measured as a share of these expenses in the cost of the final product. We form a scale based on the criterion "Expenses" (share of expenses) out of three estimates:

$$
\Xi^{1}=\langle\text { low, medium, high }\rangle
$$

The criterion of "User Satisfaction" characterizes the ability of a logistics system to meet the needs of its customers. This criterion is integral in nature, because it can be broken down into such components as the assessment of the conformity of the quantity of delivered goods to the order, compliance with the quality characteristics of the goods ordered, compliance with the price of the delivered goods to the market, and others. We will form a scale of estimates for the criterion of "User Satisfaction" similar to the previous scale:

$$
\Xi^{2}=\langle\text { high, medium, low }\rangle
$$

The "Time Indicators" criterion intersects with the previous criterion, but is not a subset of it, so the time indicators can be assessed not only from the point of view of the end user but also from the point of view of the owner of the logistics system. In this case, time characteristics come to the fore due to the rhythmic functioning of the logistics system and are of no interest to the end user, but are very important for the owner of the logistics system. Scale for "Time Indicators":

$$
\Xi^{3}=\langle\text { good, sutisfying, non - sutisfyinglow }\rangle
$$

The criterion "Assets" characterizes the efficiency of the use of the capital invested in facilities and equipment, as well as the working capital invested in inventories. Asset management assessment shows how fast current assets (including inventories) are being processed and how successfully the investments invested in them are being recouped. The qualitative scale according to this criterion may look identical to the previous scale:

$$
\Xi^{4}=\langle\text { good, sutisfying, non - sutisfyinglow }\rangle
$$

According to the given system of estimation of logistic systems $\Xi^{L S}=\left\langle\Xi^{1}, \Xi^{2}, \Xi^{3}, \Xi^{4}\right\rangle$ any logistics system will receive one of eighty-one multi-criteria evaluations. The number of ratings of the evaluation system $k$ is equal to the product of the capacity scales of the criteria:

$$
k=\prod_{i=1}^{n}\left|\Xi^{i}\right|
$$


where $n$ - the number of the criteria in the evaluation system, and $\left|\Xi^{i}\right|$ - the capacity of $i$-scale (number of ratings on the scale).

Now let us consider in detail the criteria for the LIS evaluation. As it has been noted above, the main functional criterion for the evaluation of a LIS management system for the owner of a logistics system is the criterion of the adequacy of the logistics system management. This criterion characterizes the extent to which the LIS allows the use of the logistics systems potential. The best evaluation according to this criterion is the ability to implement any management solution of the logistics system with a given accuracy and acceptable time parameters through the LIS, as well as the ability to predict the consequences of such a solution.

Thus, we introduce separate criteria for each of the above characteristics of the logistics system management perfection:

$-\mathrm{K}^{M C}=\langle$ high, medium, low $\rangle$ - the criterion of " management completeness ", which allows us to assess the availability of the implementation of any managerial decision through LIS;

$-\mathrm{K}^{M A}=\langle$ high, medium, low $\rangle-$ the criterion of "management accuracy", which allows to evaluate the accuracy of the transfer of management decisions from the LIS to the logistics system;

$-\mathrm{K}^{T C}=\langle$ high, medium, low $\rangle-$ the criterion "time characteristic", which allows to estimate the speed of obtaining the current state of the logistics system and its reflection in the LIS;

$-\mathrm{K}^{P}=\langle$ high, medium, low $\rangle-$ the criterion of "predictability", which must be evaluated within the framework of the projected logical system for the population in relation to a particular administrative management.

Now we will consider the main criteria by which an information system is evaluated in information management [12]. Any information system goes through the stages of design, development, testing and implementation. This requires resources, primarily time, funds and performers. The volume and quality of these resources are determined by the technologies that are used to create the LIS. These technologies may be innovative, which can cause the risk of unsuccessful implementation, and may be well-tested, but with the limited capabilities.

In information management, much attention is paid to such an indicator as TCO (Total Cost of Ownership) - the total cost of ownership of information systems, which includes both direct and incidental expenses of the organization for the operation of its information systems. Usually the introduction of new information systems increases the value of this indicator. But the new information system can lead to a decrease in this indicator, for example, by reducing the cost of consumables (paper, toner, etc.), or the wages of operating personnel, or due to the refusal to use the equipment.

So, we will restrict ourselves to the following criteria:

$-\mathrm{K}^{D C}=\langle$ low, medium, high $\rangle-$ the criterion of "development cost", which allows you to assess the cost of design, development, testing and implementation of LIS, including the cost of training personnel for operation;

$-\mathrm{K}^{D T}=\langle$ short, medium, long $\rangle-$ the "development time" criterion, which allows to evaluate the time characteristics required for the creation and implementation of LIS; as a rule, proven technologies benefit from this indicator over the innovative ones;

$-\mathrm{K}^{C O}=\langle$ decreases, stable, increases $\rangle$ - the criterion of "change in total cost of ownership";

$-\mathrm{K}^{E A}=\langle$ high,medium, low $\rangle$ - the criterion of " availability of executors ", which characterizes the presence of executors who can carry out the development of LIS; as a rule it is low for the newest technologies and high for well-known. 
Thus, we have a LIS evaluation system, consisting of eight criteria:

$$
\mathrm{K}^{L I S}=\left\langle K^{M C}, K^{M A}, K^{T C}, K^{P}, K^{D C}, K^{D T}, K^{C O}, K^{E A}\right\rangle
$$

The built system of criteria consists of eight components. If we limit ourselves to only three estimates for each of the criteria, i.e. $38=6561$ different estimates for possible alternatives. It is clear that the number of estimates for some of the criteria can be increased, but this will lead to an increase in the total number of potential alternatives.

When building the LIS evaluation system as a decision support system, it is necessary to give the opportunity to expand (narrow down) the estimates according to the criteria, to give the opportunity to set additional or ignore the existing criteria and to take into account the personal preferences of the decision-maker. The consideration of the personal preferences is actually the formation of weightings for the criteria. The importance of the criteria (criteria weights) is situation-based, i.e. it varies from person to person and from task to task.

With the help of this system, it is possible to compare LISs, both those that actually exist and those that are only being designed. For the LISs that are only being designed, it is necessary to use actual and planned indicators.

\section{RESEARCH LIS}

The design of a LIS needs to be started by identifying the tasks it should accomplish. This will determine the hardware-software platform on which the LIS will be built. In [13] there has been given an analysis of the hardware-software platforms used in modern logistic systems and the capabilities they provide in the management of the logistic system. The next stage of the LIS design is the determination of its architecture. According to the analysis of a typical IPMS architecture [9], it was found that the most promising modern approach to create an IPMS, or its separate subsystems, is the development of an information system on two- or three-tier architecture. For the information systems of the separate enterprise level the two-tier architecture is enough, and three-tier and more complex architectures are used for corporate information systems.

The purpose of the development of the research LIS was the proving of the thesis that the mathematical model of the material flow [6] is of practical importance and can be used as a theoretical basis for the development of a software product, in particular for the information system of internal logistics management of the enterprise. For the implementation of the research LIS there was chosen a two-linked architecture of the information system with the implementation of both links on Win32, as the most minimally complicated architecture, which is capable to support the information system, which meets modern requirements to the IPMS.

In [8], a data model was proposed to support the multi-set model of material flow. This data model was used as the basis for the development of the research LIS. A free version of MySQL Community Server 5.6.22 was used for the implementation of the research LIS [14]. The choice of MySQL database was due to such factors as its free of charge, reliability, support of all necessary data types, and its compliance with the SQL standard.The trial version of Delphi by Embarcadero Corporation was chosen as a development tool. Delphi has established itself as one of the best tools for the application and system programming. In addition, the latest versions of Delphi support the development of programs for all major operating systems, namely Win32, Win64, Mac OS X, iOS and Android; it allows the same code of the program to be compiled for different platforms. Embarcadero Corporation provides an opportunity to use the thirty-day trial version of its product free of charge. 
To speed up the development process, ORM (Object-Relational Mapping) technology was used. The ORM technology has recently been gaining wider application in software development practice. The term itself is usually translated as object-relational mapping, i.e. a reflection of the system of classes in the relational structure (database scheme) and vice versa. The class term here is used in the paradigm of object-oriented programming. The use of the trial version of EntityDAC product [15] has allowed to speed up the process of development of the LIS management system. When using ORM, you can take one of the three approaches to a program development [15]: Database-First; Model-First; Code-First. In the case of the development of the research LIS, the Database-First approach was used. This is due to the developer's desire to consider the entire database structure and make it easier to migrate to another DBMS.

The analysis of the research LIS. Taking into account the purpose of creating the research LIS, the minimal functionality was implemented in it, which allowed using the program for managing the internal logistics of the enterprise. In particular, the following functionality was implemented in the research LIS:

- storage of the information about production plans;

- storage and processing of the information about the location of raw materials, parts and other consumables;

- storage of the information about the movement between production modules and warehouses;

- storage and processing of the information about transport vehicles;

- planning of the material flow;

- control of the material flow;

- formation of an accompanying information flow;

- obtaining the reporting information.

After the trial operation, the research LIS was evaluated according to some criteria of the above system $\mathrm{K}^{L I S}$. The research LES received the best grades according to the "time characteristics" criteria $\left(\mathrm{K}^{T C}\right)$, "management accuracy" $\left(\mathrm{K}^{M A}\right)$, "development cost" $\left(\mathrm{K}^{D C}\right)$ and "development time" $\left(\mathrm{K}^{D T}\right)$. The worst grade was obtained on the criterion of "predictability" $\left(\mathrm{K}^{P}\right)$, because this functionality was not implemented in the research LIS. By the criterion " management completeness " $\left(\mathrm{K}^{M C}\right)$ the research LIS was rated as "medium". No assessment was made according to the criteria of "change in total cost of ownership" $\left(\mathrm{K}^{C O}\right)$ and "availability of executors " $\left(\mathrm{K}^{E A}\right)$.

As a result of the trial operation of the research LIS, it was recognized that the use of a multiset material flow model is promising and makes sense in creating a full version of the LIS based on this model.

\section{CONCLUSION}

The study analyzed the criteria for the evaluation of logistics systems and provided an example of the formation of the evaluation system based on four criteria by a qualitative scale. The LIS evaluation system was also established which is also based on the use of criteria by qualitative scales.

The study also analyzed the modern technologies of design and development of information systems and justified the choice of a two-tier architecture for the development of a research LIS. The choice of the DBMS and LIS development tool was also justified.

The last chapter of the study presents the analysis of the research LIS evaluation, as a result of which a multi-set material flow model is considered promising and to be the model that makes sense for the development of a fully functional LIS. 
The author sees further development of the research area in the improvement of the multi-protective material flow model based on the results of testing the research LIS.

\section{REFERENCES}

[1] Magal Simha R, Jeffrey W. Integrated Business Processes with ERP Systems. J Wil Sons, 2011, 358.

[2] Enterprise Resource Planning. Wikip http://uk.wikipedia.org/wiki/ERP.

[3] Enterprise Resource Planning. Electr vers: http://www.gartner.com/it-glossary/enterpriseresource-planning-erp.

[4] Gavrilov D. Upravlenie proizvodstvom na baze standarta MRP II. Man of an ent on the base of MRP, 2008, 416.

[5] Hryshko SV, Hutsa OM, Sukhomlinov AI. Modeliuvannia vyrobnychoi lohistyky v umovakh perebudovy pidpryiemstva. Rad i infor, 2013, 2, 31-34.

[6] Sukhomlinov AI. Modeliuvannia materialnoho potoku u vyrobnychii lohistytsi. Syst obrob inform, 2013, 2 (109), 294-298.

[7] Petrovskiy AB. Prostranstva mnozhestv i mul'timnozhestv. Moscow: Editor URSS 2003, 248.

[8] Sukhomlinov AI. Zadachi modeliuvannia lohistyky ta proektuvannia informatsiinykh system vyrobnychoi lohistyky. Inform Proc Syst 2013, 5(112), 162-170.

[9] Sukhomlinov AI. Modeliuvannia komponentiv pidtrymky pryiniattia rishen v informatsiinykh systemakh vyrobnychoi lohistyky. Inform Proc Sys, 2013, 8(115), 264-267.

[10] Larichev OI. Teoriya i metody prinyatiya resheniy. Textbook. - Moscow: Logos, 2000, 296.

[11] Larichev OI. Verbal'nyy analiz resheniy. Moscow: Nauka, 2006, 181.

[12] Zhezhnych PI. Tekhnolohii informatsiinoho menedzhmentu. Inf manag techn, 2010, 260.

[13] Omarov MA, Sukhomlinov AI. Modelirovanie programmnogo obespecheniya avtomatizirovannoy sistemy upravleniya proizvodstvennoy logistikoy. Avtomat i sovrem tekhnol, 2014, 6, 18-22.

[14] Download MySQL Community Serverю. Access mode:http://dev.mysql.com/downloads/mysql.

[15] EntityDAC - ORM for Delphi with LINQ support. Access mode:http://www.devart.com/entitydac 